\title{
A journey into recycling of waste elastomers via a novel type of compatibilizing additives
}

\author{
L. Simon-Stöger ${ }^{*}$, Cs. Varga, E. Greczula, B. Nagy \\ Institutional Department of MOL Hydrocarbon and Coal Processing, University of Pannonia, 8200 Veszprém, Hungary
}

Received 28 September 2018; accepted in revised form 22 December 2018

\begin{abstract}
Nowadays successful recycling of rubber waste has been one of the greatest challenges in waste management. Difficulties in mechanical recycling are especially caused by the variability of raw materials, therefore, a processing simply combining them usually results in end-products with poor mechanical stability. Drawbacks of mechanical recycling of mixed plastics and blends of plastics and rubbers can be overcome by application of compatibilizing additives. Taking the commercial types into account only a few general kinds are available and their effectiveness is hindered by the structure as it cannot be fitted to the chemical structures of plastics processed together. Our study has been addressed to give a comprehensive outlook into a rubber recycling process and successful application of compatibilizing strategies for improving mechanical performance of waste elastomer containing polypropylene. Investigations have been carried out on effective elastomer concentrations, meanwhile on elastomer ratios of various types to each other and on proper structures of compatibilizers. Various mechanical properties could be improved even by $44 \%$ due to experimental additives compared to uncompatibilized blends. Mechanical test results have been confirmed by SEM, rheology and FT-IR, to name some of them.
\end{abstract}

Keywords: polymer blends and alloys, waste elastomer, compatibilizing additive, ground tire rubber, polypropylene

\section{Introduction}

Waste rubbers, especially ground tire rubber (GTR) and ethylene-propylene-diene monomer (EPDM) can be recycled via incorporating them into polymers, mainly into thermoplastic ones. A great number of research [1-12] was published on blending of waste elastomers as fillers into polyolefins in order to extend application areas while offering an advantageous way of mechanical recycling. Recycling of rubbery waste materials have also become a necessary issue to be solved for several reasons.

It is not only the European Union legislation that requires this way of recycling but also the efforts on decreasing environmental loading of solid wastes, furthermore the economic expectations are becoming stricter and stricter. Since the automotive industry heavily relies on rubbers (EPDM, components of different types of rubbers like styrene-butadiene rubber
(SBR), butadiene rubber (BR), natural rubber (NR)) in various parts of an automobile or a motorbike (tires, weather-strips, hoses, vibration insulators and miscellaneous parts, etc.) high level of waste management has to be supplied for end-of-life products considering the even growing demand in the following decades as well.

On the one hand complex composition of tires might be mentioned among the difficulties of GTR recycling $[13,14]$. This issue is present even after removing steel cord and synthetic fibers during grinding. On the other hand the particle size and its distribution play important roles in recycling strategies. Difficult equipment lines and serious conditions are required if such a material of cross-linked structure is reprocessed. That was due to the basic designing aspects of rubbery products in regard to their suitable mechanical strength and outstanding flexibility, 
meanwhile good resistance against extreme environmental conditions like high $\left(100^{\circ} \mathrm{C}\right)$ and even low $\left(-30^{\circ} \mathrm{C}\right)$ temperatures and aggressive chemicals are also expectations [15].

Several pieces of information $[2,7,14,16-20]$ can be found in the literature about the influence of the mean size of rubber particles, while impact assessment of surface roughness is a less studied field [7,21]. The large particle size of waste elastomer used in blends is reported to be one of the two main factors contributing to the poor mechanical properties generally observed in waste elastomer/polyolefin blends. Therefore blending of filler with lower particle size is desired for achieving optimum blend properties [16]. The role of rubber particle size was studied by Hrdlička et al. [17]. Effects of six waste tire rubber fractions (between 120-650 $\mu \mathrm{m}$ ) were examined on the mechanical properties of low density polyethylene (LDPE) based blends. Best results were achieved by incorporation of the smallest particles $(120 \mu \mathrm{m})$. GTR was partially replaced by EPDM and styrene-ethylene-butylene-styrene (SEBS), which are adhesion components, having beneficial effect on tensile strength and elongation at break.

The influence of particle size is inconsiderable at higher concentration (above $50 \mathrm{wt} \%$ ) of waste elastomer due to poor interphase playing a dominant role [14]. It can be stated that mechanical property parameters of the materials obtained decrease with increasing rubber content and its particle size $[2,7,14,16,19]$. Sonnier et al. [20] found, that the particle size of GTR in a defined range (from 380 to $1200 \mu \mathrm{m}$ ) have no significant effect on the material properties (except elongation at break).

With the decrease in particle size, the entire shear viscosity curve is shifted to a significantly higher level. The viscoelastic properties of diphase polymer materials depend on the size and deformability of the dispersed phase. Deformability of the dispersed domains is also greatly affected by their sizes [18].

The lack of the suitable adhesion between components is reported to be the other main factor beside particle size and its distribution for a product with poor mechanical stability. Incorporation of maleic-anhydride grafted polyethylene (PE-g-MA) or polypropylene (PP-g-MA) into waste rubber containing polyolefin blend can be mentioned as an effective method of compatibilization. Song et al. [22] applied maleic-anhydride grafted high density polyethylene (HDPE- $g$-MA) for boosting the interfacial interaction in linear low density polyethylene (LLDPE)/GTR wherein the latter suffered from various levels of degradation. GTR was degraded at different temperatures by extrusion. Addition of HDPE- $g$-MA enhanced the interfacial interaction of blend components and contributed to the more homogeneous dispersion of GTR in LLDPE and also to the decrease of particle size.

Blends of HDPE and EPDM were examined in composition of $40 / 60$ and $80 / 20$ by Stelescu et al. [23]. PE- $g$-MA (5 and $10 \mathrm{wt} \%$ ) or dynamic vulcanization by phenolic resins were applied as a compatibilizer for improving mechanical properties of the blends. Elongation at break, residual elongation and tear strength was found to be improved by PE-g-MA in any concentration increasing contact angle and hydrophobicity of the blend surface. Tensile and tear strengths increased in blends based on phenolic resin containing vulcanization agent although the degree of enhancement was far behind the improvement experienced in grafted polymer compatibilized blends, as in the latter case residual elongation was four times higher compared to the uncompatibilized blend mentioned as an example.

Hassan et al. [24] investigated mechanical and thermal properties of the blend of devulcanized rubber (DR)/PP/EPDM 45/25/30 blend by adding dicumyl peroxide (DCP) in different concentrations and gamma irradiation doses at various levels. Peroxide and radiation dynamic vulcanization showed synergetic effect on the mechanical properties, which revealed in the improvement of elastic modulus, tensile strength and elongation at break.

Formela et al. [25] investigated the effect of interfacial modification by adding commercial non-polar elastomer (two grades of SBS (styrene-butadienestyrene) copolymers) to the LDPE/GTR blends. Blends with $50 \mathrm{wt} \%$ LDPE content showed the best elongation at break and tensile strength. SBS was able to enhance compatibility between LDPE and GTR based on its partial miscibility in both of them.

Mali et al. [26] applied triallyl cyanurate as a co-agent in the blend of HDPE/RTR (reclaimed tire rubber) $50 / 50$ in the presence of gamma irradiation. Best properties were acquired by gamma irradiation of HDPE/RTR blends containing $3 \mathrm{wt} \%$ triallyl cyanurate at $150 \mathrm{kGy}$.

Based on the literature survey application of compatibilizing additives was proposed to be necessary since chemical structure of waste elastomers and 
polyolefins differ significantly, and therefore, the main purpose of our study was to investigate the effects of waste elastomer filler content and chemical structure of compatibilizers which were synthesized at our Department. The suitable structure of experimental additive was aimed to be found that can manage to improve both tensile and impact properties of the blends. A commercial additive was also compared to the experimental ones in regard to effectiveness.

\section{Experimental}

\subsection{Materials}

The matrix material was a commercial polypropylene (PP) homopolymer supplied by Braskem (H73452RNA, Sao Paulo, Brazil). The PP had a melt flow index of $50 \mathrm{~g} / 10 \mathrm{~min}\left(230^{\circ} \mathrm{C}, 2.16 \mathrm{~kg}\right)$. Compression molded samples from PP granules had tensile strength of $25.8 \mathrm{MPa}$, tensile modulus of $1610 \mathrm{MPa}$ and elongation at break of $3.5 \%$. Specimens had Charpy impact strength of $2.2 \mathrm{~kJ} / \mathrm{m}^{2}$ at room temperature and $1.7 \mathrm{~kJ} / \mathrm{m}^{2}$ for samples cooled to temperature $5^{\circ} \mathrm{C}$.

Waste ground tire rubber (Hungarojet Ltd., Budapest, Hungary) and waste ethylene-propylene-diene rubber (SZEMES Industrial Rubber Sealing Ltd., Balatonalmádi, Hungary) were blended into the polyolefin as filler materials with different concentrations. Waste raw materials were used as available in the industry and no further grinding was required for the study, since decreasing of the particle size is a really expensive method.

Particle size distribution of the fillers was separately represented in Figure 1. Waste EPDM had wider particle size distribution and also significant amount of

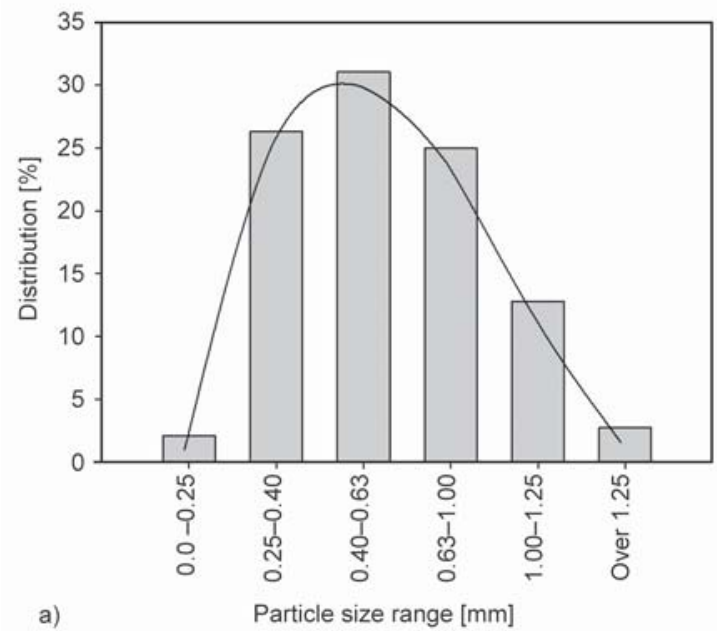

Table 1. Properties of GTR.

\begin{tabular}{|c|c|c|}
\hline Physical properties & Measurement method & [wt\%] \\
\hline Adherent moisture content & ASTM D1509-18 & 0.4 \\
\hline Part, soluble in acetone & ASTM D297-15 & 8.5 \\
\hline Part, soluble in chloroform & ASTM D297-15 & 0.3 \\
\hline$\Sigma$ isoprene content & ASTM D297-15 & 58.5 \\
\hline NR+IR content & ASTM D297-15 & 36.5 \\
\hline Carbon black content & ASTM D297-15 & 27.2 \\
\hline Ash content & ASTM D297-15 & 5.1 \\
\hline \multicolumn{3}{|l|}{${ }^{*}$ Compatibility index: 2.68} \\
\hline \multicolumn{3}{|c|}{$\mathrm{NR}+\mathrm{IR}$ content [wt $\%]$} \\
\hline
\end{tabular}

the particles belonged to higher particle size domains. More than half of the particles were found to be over the $0.4 \mathrm{~mm}$ particle size.

Main physical properties and measuring methods of the GTR were shown in Table 1.

GTR particles can be encapsulated by EPDM, due to not only its higher compatibility to the polyolefin phase via the ethylene and propylene groups in the chain but also being capable for emulsifying effect at the surface [11].

It was found in the study of Lima et al. [27] that large particle size $(0.841 \mathrm{~mm})$ of EPDM might be responsible for EPDM not being able to cover the GTR particles, therefore the encapsulation could not be realized completely. The optimal covering of GTR by EPDM depends on the size of rubber particles and on the applied elastomer ratio (EPDM/GTR) [25].

One of the major issues in the field of homogenization of particle type fillers in a satisfactory way in polymer matrices can be successfully managed by compatibilization. Several types of compatibilizing additives, like maleic-anhydride grafted polyolefins are commercially available and widely used in scientific

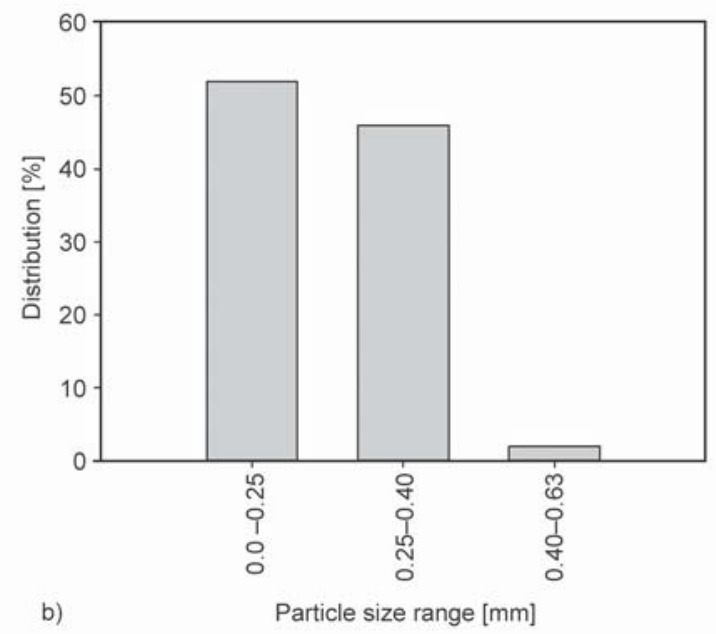

Figure 1. Particle size distribution of (a) EPDM and (b) GTR. 


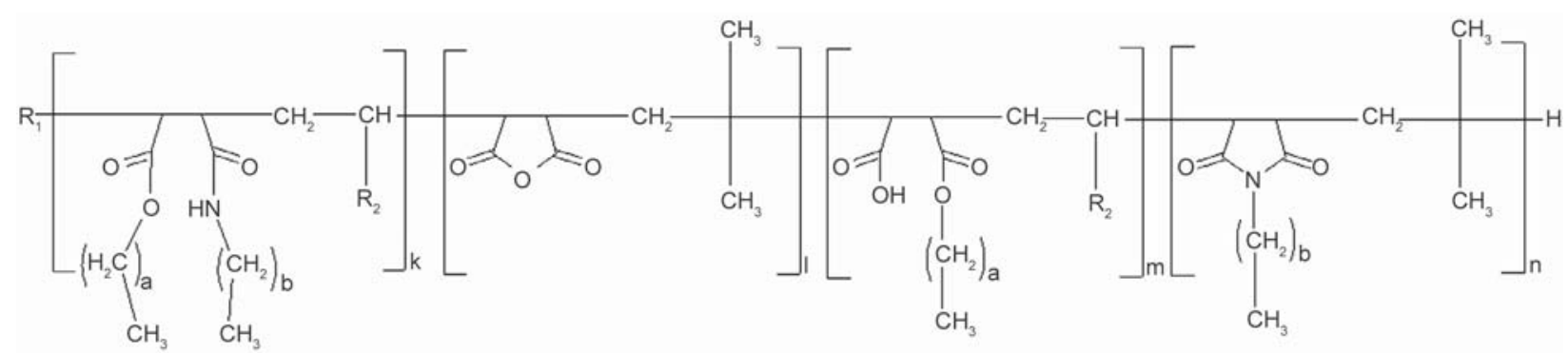

Figure 2. Structure of the derivatives of the experimental olefin-maleic-anhydride copolymer $\left(\mathrm{R}_{1}\right.$ : alkyl group with length of the olefinic monomer $\left(\mathrm{C}_{16}-\mathrm{C}_{18}\right) ; \mathrm{R}_{2}$ : alkyl group with $\mathrm{R}_{1-2}$ carbon number; a: 3-40, b: 3-32; $\mathrm{k}$ : 0.2-2; 1: 1-7; $\mathrm{m}:$ 1-7 and $\mathrm{n}: 0.3-2)$.

research. Our experimental work focused on the effects of different kinds of compatibilizers, especially on experimental olefin-maleic-anhydride copolymer based ones (Figure 2) synthesized at our Department [28].

Functional groups meant one of the main differences comparing the two families of compatibilizers applied. Commercial one ((PP-g-MA, Licomont AR 504 - assigned as LAR 504), Clariant, Muttenz, Switzerland) contained only one type of functional group, namely maleic-anhydride, meanwhile experimental additives might have contained up to four different functional groups as illustrated in Figure 2. Possibility of the presence of that four kinds of functional groups (anhydride, half-ester, ester-amide and imide) offered the opportunity of changing polarity of the compatibilizer, therefore, fitting the structure to raw materials combined.

Furthermore, molecular weight of the additives differed significantly from each other that was an influencing factor in blend processing due to the differences in physical consistency. Five experimental additives were studied with main analytical properties shown in Table 2.

Some rheological properties (complex viscosity, storage and loss modulus) were also measured as function of the temperature.
The rheological tests of the experimental additives were performed by a dynamic shear rheometer (MCR 201, Anton Paar, Graz, Austria) in different temperature ranges of -20 to $70{ }^{\circ} \mathrm{C}$.

Infrared spectroscopy was used to collect structural information with a TENSOR 27 type (Bruker, Billerica, Massachusetts, USA) FTIR spectrometer (resolution: $3 \mathrm{~cm}^{-1}$, illumination: $\mathrm{SiC}$ Globar light, detector: RT-DLaTGS type) in the $400-4000 \mathrm{~cm}^{-1}$ wave number range.

\subsection{Sample preparation}

Blends were prepared by a two-roll mill (LRM-100, LabTech Engineering Ltd., Samutprakarn, Thailand). Temperature of rollers were set to 180 and $140^{\circ} \mathrm{C}$. Roller of the higher temperature was rotating faster, friction ratio was set to 1.7. The highest temperature was considered to be of max. $180^{\circ} \mathrm{C}$ for preventing waste elastomers from serious degradation during processing. Waste GTR and/or EPDM were added to the melt of polypropylene. Waste elastomers were applied between 0 and $50 \mathrm{wt} \%$ in the polyolefin matrix, the duration of the blending was influenced by the composition (from 7 to 10 minutes). The ratios of waste elastomers were selected to be 1:3, 1:1 and 3:1. Compatibilizing additives were added to the blend in $0.1 \mathrm{wt} \%$ after homogenization of the components.

Table 2. Main properties of compatibilizing additives.

\begin{tabular}{|l|c|c|c|c|c|c|}
\hline \multicolumn{1}{|c|}{ Property } & AD-1 & AD-2 & AD-3 & AD-4 & AD-5 & LAR 504 \\
\hline Acid number $\quad[\mathrm{mg} \mathrm{KOH/g} \mathrm{sample]}$ & 57.3 & 56.0 & 45.9 & 50.6 & 9.4 & 41.00 \\
\hline Saponification number $[\mathrm{mg} \mathrm{KOH/g} \mathrm{sample]}$ & 166.4 & 169.8 & 147.0 & 148.5 & 105.7 & - \\
\hline Molecular weight $[\mathrm{g} / \mathrm{mol}]$ & 3520 & 4310 & 4010 & 3610 & 4180 & - \\
\hline Polydispersity index, $M_{\mathrm{w}} / M_{\mathrm{n}}$ & 1.299 & 1.355 & 1.041 & 1.099 & 1.566 & - \\
\hline Anhydride & 0.33 & 0.31 & 0.23 & 0.32 & 0.06 & 1.00 \\
\hline Half-ester & 0.31 & 0.29 & 0.43 & 0.28 & 0.00 & - \\
\hline Ester-amide & 0.18 & 0.20 & 0.17 & 0.20 & 0.47 & - \\
\hline Imide & 0.18 & 0.20 & 0.17 & 0.20 & 0.47 & - \\
\hline
\end{tabular}


Finally sheets were compression molded from samples by a laboratory press (CARVER 3853-0, Carver, Inc., Savannah, Georgia, USA) at $180^{\circ} \mathrm{C}$ for ten minutes and cooled down to room temperature within ten minutes. Specimens with dimensions of $10 \mathrm{~mm} \times 2.4 \mathrm{~mm} \times 170 \mathrm{~mm}$ were cut from those sheets for mechanical tests.

\subsection{Measurements}

Two different mechanical properties were investigated. One was the Charpy impact strength determined: on samples cooled to $5^{\circ} \mathrm{C}$ and at room temperature. The test was carried out on V-notched samples by an impact testing machine (CEAST Resil Impactor 6967.000., CCSi, Inc., Akron, Ohio, USA). Data represented were the average of five parallel measurements with their standard deviations.

The other method was the measurement of tensile properties of samples with a single column universal tensile testing machine (INSTRON 3345, Instron, Norwood, Massachusetts, USA). Crosshead-speed was set to $90 \mathrm{~mm} / \mathrm{min}$, temperature was $24^{\circ} \mathrm{C}$ and relative humidity was $53 \%$ during the tests. Data measured were elongation at break [\%], tensile modulus $[\mathrm{MPa}]$, and tensile strength $[\mathrm{MPa}]$. Data represented were the average of five parallel measurements with their standard deviations.

\section{Results and discussion}

Our experimental work was carried out to investigate effects of both filler concentration and compatibilizing additives. On the first hand filler concentration and advantageous ratio of different fillers were studied on mechanical properties of PP based blends produced without compatibilizer. On the second hand various compatibilizing additive structures were tested to find the suitable one for blends with balanced mechanical performance.

\subsection{Effects of filler concentration}

Significant improvement could be achieved in Charpy impact strength by incorporation of waste elastomers into PP compared to values of the neat matrix, which were low at any temperature (Figure 3 ). An average improvement of $177 \%$ could be experienced in impact strength with blends containing elastomers in 10 and $50 \mathrm{wt} \%$ at room temperature. There was a similar change recognized in the case of the cooled samples where the increment was $213 \%$.

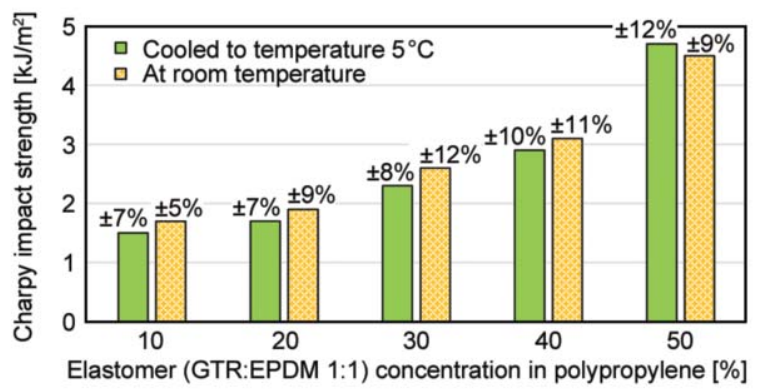

Figure 3. Change in Charpy impact strength with elastomer concentration (neat $\mathrm{PP}$ at room temperature: $2.2 \mathrm{~kJ} / \mathrm{m}^{2}$, neat PP cooled to temperature $5^{\circ} \mathrm{C}$ : $\left.1.7 \mathrm{~kJ} / \mathrm{m}^{2}\right)$.

Remarkable differences cannot be noticed between the values of cooled or at room temperature measured samples at identical elastomer concentrations which might be advantageous in terms of usage of the blend under disparate temperature conditions. It can be established that energy expressed during the impact test was absorbed effectively in case of high elastomer concentrations at both temperatures $[10,16]$.

Elastomer concentration was increased up to $50 \mathrm{wt} \%$ since advantage on an earlier literature stated fact by Punnarak et al. [29] was required to be taken off. According to our results, improvement could be recognized up to $50 \mathrm{wt} \%$ waste elastomer in impact strength due to good absorption impact energy but further increase of rubber content (over $50 \mathrm{wt} \%$ ) probably caused thicker defect points in the blend inducing a split in the layer structure inside providing a shorter path for fracture propagation [29].

According to literature survey among the influencing factors not only the different compositions had to be mentioned but also the particle size and distribution of the raw materials. It is a widely known fact that fracture toughness of polymers can be significantly boosted by incorporating rubber particles. The deformation of PP/rubber blends is accompanied by stress whitening. Cavitation of rubber particles relieves the stress triaxially in the matrix, suppressing the likelihood of matrix crazing and promoting plastic deformation in the matrix by shear yielding. The toughening effect is generally enhanced when a region of large plastic deformation spreads out over a large volume in the material. Formation of large cavities is advantageous since they are more likely to become unstable. Large particles contain several cavitation sites and the conditioning for cavitation is apparently more favorable near the interface than in the centre 


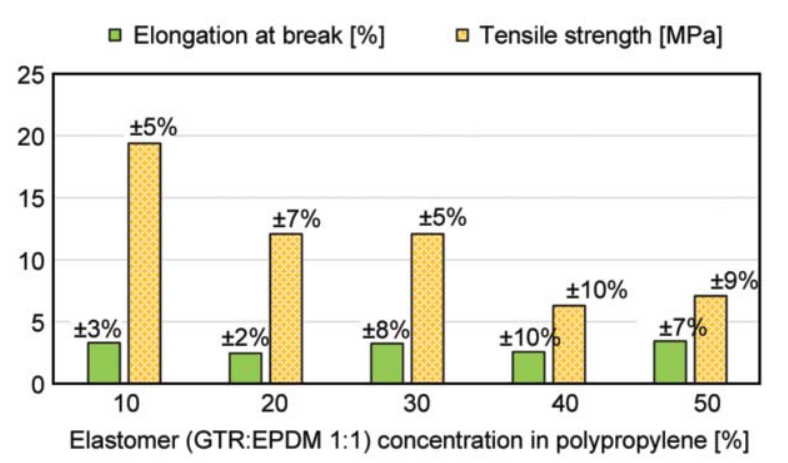

Figure 4. Change in elongation at break and tensile strength with elastomer concentration (elongation at break and tensile strength of neat PP: $3.5 \%$ and $25.8 \mathrm{MPa}$ ).

of a rubber sphere. Thereby in the larger particles several small cavities are formed instead of one large cavity [30-32].

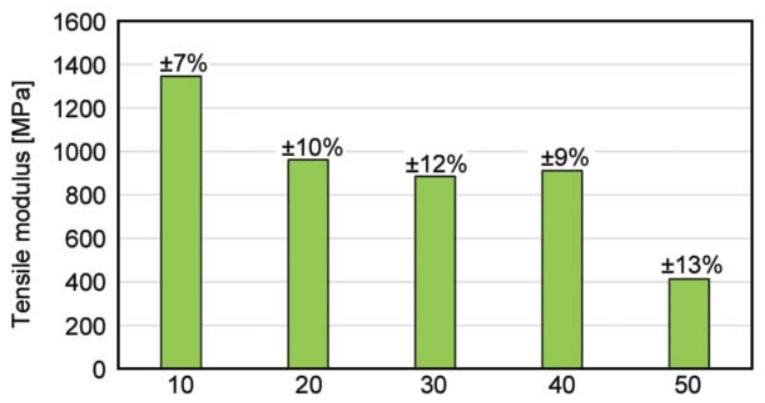

a) Elastomer (GTR:EPDM 1:1) concentration in polypropylene [\%]

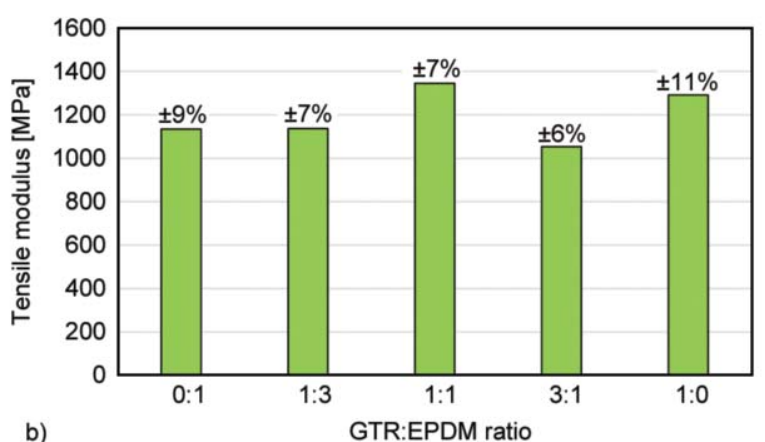

b)

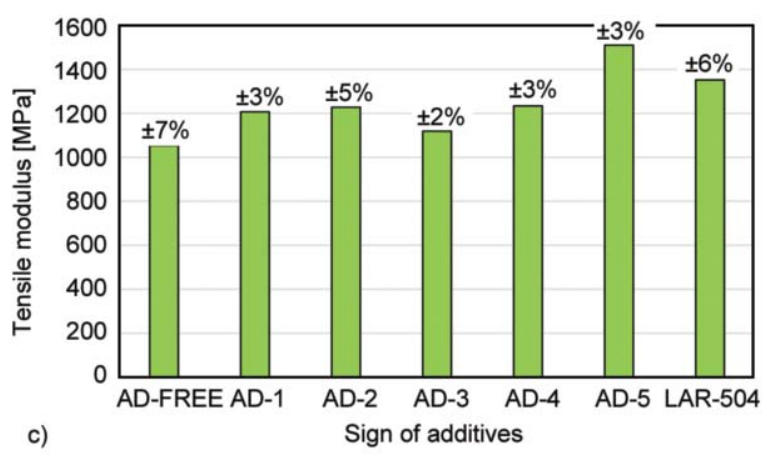

Figure 5. Change in tensile modulus (a) with elastomer concentration (tensile modulus of neat PP: $1610 \mathrm{MPa}$ ), (b) with different elastomer ratios in 90/10 PP/ GTR:EPDM, (c) in the presence of experimental compatibilizers and a commercial one $(0.1 \mathrm{wt} \%)$ in 90/10(1:1) PP/GTR:EPDM.
The results of elongation at break and tensile strength were illustrated in Figure 4.

Values of elongation at break of the samples (Figure 4.) did not change in order of magnitudes with increasing concentrations of elastomers related to neat matrix, therefore, samples in our research were denoted as thermoplastic blends, since the phrase of 'thermoplastic elastomer' can be used only for blends which have a value of elongation at break at least $100 \%$ [14]. The low level of elongation at break might be due to the way of blend production on the one hand and on the other hand due to the lack of adhesion between the filler materials and matrix but the relatively large particle size of elastomers and their crosslinking behavior might be responsible as well.

In the case of tensile strength of GTR:EPDM (Figure 4.) up to $10 \mathrm{wt} \%$ a decrease by $25 \%$ was experienced compared to the neat PP, meanwhile blends containing 20 and $30 \mathrm{wt} \%$ waste elastomer showed same levels of tensile strength. The situation was the same comparing tensile strength of samples with 40 and $50 \mathrm{wt} \%$ waste elastomers that can provide not only the opportunity and flexibility for increasing waste content but also improving recycling if the value of tensile strength is high enough. Considering both impact and tensile strengths application of 30 wt $\%$ waste elastomer may be more advantageous in order to avoid the since drastic change in tensile strength in blends with more than $30 \mathrm{wt} \%$ waste elastomer.

Waste elastomer concentration did not have significant effect on tensile modulus up to $20 \mathrm{wt} \%$ (Figure 5a) forasmuch it is measured at an initial stage of the stress-strain curve where the interfacial phenomenon between components is not essentially influential [33, 34], meanwhile and rubbery materials could be generally characterized by smaller tensile modulus.

The results revealed that incorporation of $10 \mathrm{wt} \%$ waste rubber into PP caused only $17 \%$ decreasing in the value of tensile modulus considering it to be advantageous. Based on the fact that PP was probably able to compensate the deterioration of tensile modulus up to $50 \mathrm{wt} \%$ elastomer content. Hereafter measurements were implemented with $10 \mathrm{wt} \%$ elastomer containing blends based on the results of filler concentration enhancement because among the purposes conservation or even improving of favorable tensile properties were appointed besides boosting of Charpy impact strength. 


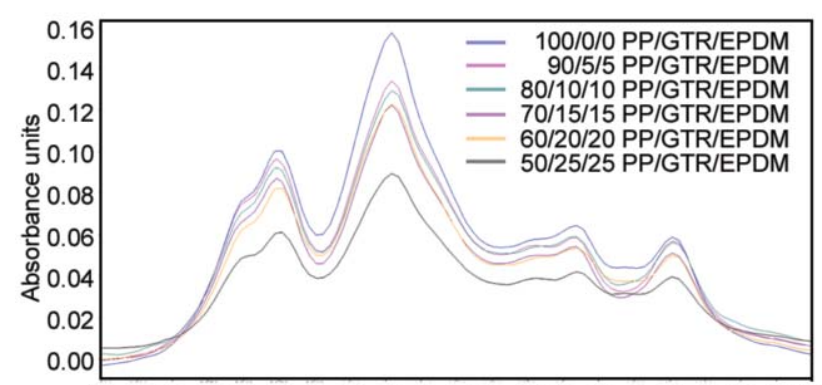

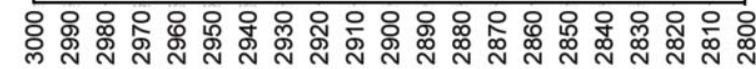

a)

Wave number $\left[\mathrm{cm}^{-1}\right]$

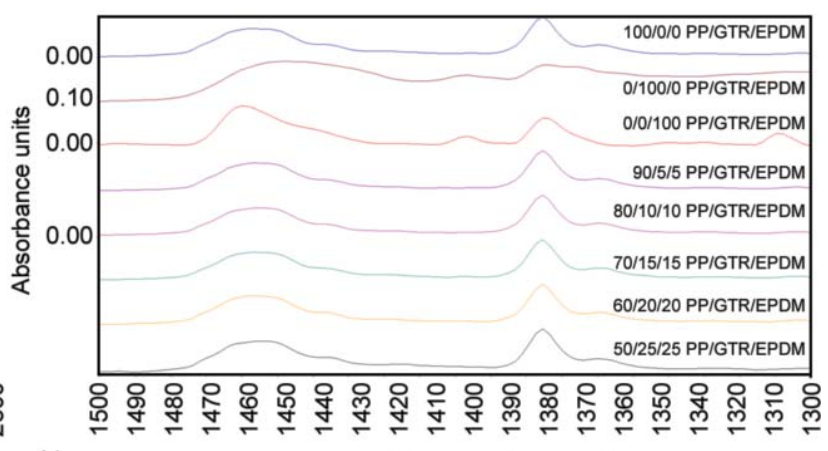

b)

Figure 6. (a) FT-IR spectra of neat PP and waste elastomer containing PP blends between wave number of 3000 and $2800 \mathrm{~cm}^{-1}$, (b) FT-IR spectra of neat PP, GTR, EPDM and waste elastomer containing PP blends between wave number of 1500 and $1300 \mathrm{~cm}^{-1}$.

The trends of literature [14] was confirmed by our results as well. The impact strength of blends improved simultaneously with deterioration of tensile strength in regard to the GTR applied with the given particle size indicating that only physical interaction might have been formed between the phases of elastomer and PP proved by the FT-IR results either (Figure 6). Spectra of the samples between 3000 and $2800 \mathrm{~cm}^{-1}$ referred to the stretching vibrations of methyl and methylene functional groups in the components. The higher the elastomer content was, the lower the intensities and their ratios were. In lower wavenumber range (from 1500 to $1350 \mathrm{~cm}^{-1}$ ) deformation vibrations of the methyl and methylene groups could be found. Since no additional functional groups appeared in the spectra of blends with various elastomer concentrations, only physical interactions were considered to be formed between the components.

\subsection{Effect of elastomer combination}

Accessibility and interoperability of raw materials might become an important issue to investigate, therefore, studies were conducted on the effects of different ratios of various types of elastomers as well.

Ratios of the waste materials (GTR:EPDM) were selected to be $0: 1,1: 3,1: 1,3: 1$ and $1: 0$ at $10 \mathrm{wt} \%$ elastomer content based on the aforementioned results. That work in the field of combining different types of elastomers can be hardly compared to literature data and results because of the waste origin of EPDM as one of raw materials in our research. However it should be emphasized that commercial EPDM was reported to function as a self-employed compatibilizer in waste rubber/thermoplastic blends [35], but recycling of it is also going to be an important waste management issue in the future.

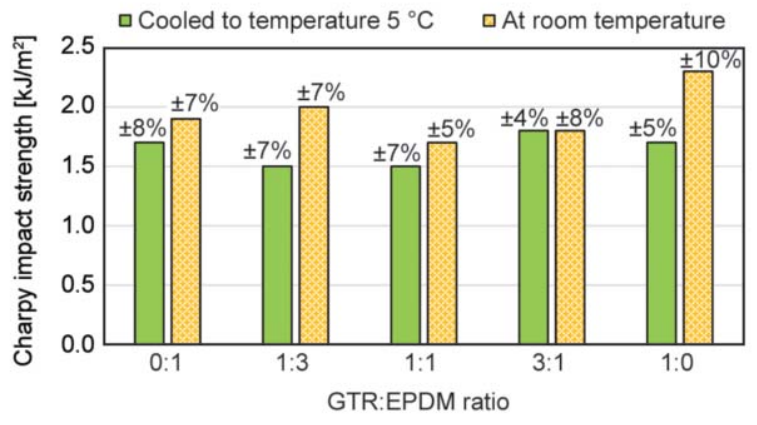

Figure 7. Effect of different elastomer ratios on Charpy impact strength in 90/10 PP/GTR:EPDM blend.

Charpy impact strength (Figure 7) measured at room temperature showed slight differences comparing the samples, namely, a change like a minimum curve was observed, where ratio of 1:1 and 3:1 (GTR:EPDM) represented the lowest values. That phenomenon disappeared in lower temperature measurements since cold side performance of the blends was almost the same for all the samples, independently from the ratios of the elastomer types investigated. Among the blends the only GTR containing one can be highlighted because of its favorable impact strength at room temperature, being higher by $21 \%$ than only EPDM containing one.

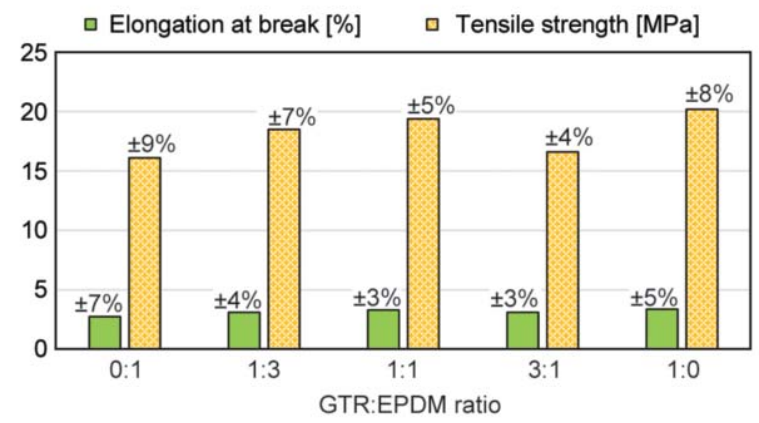

Figure 8. Effect of different elastomer ratios on elongation at break and tensile strength in $90 / 10 \mathrm{PP} /$ GTR:EPDM. 
Tensile strength (Figure 8) increased simultaneously with EPDM content in the samples containing both elastomers. Therefore, EPDM and PP seemed to be more compatible with each other than GTR and PP, considering the fact, that even the particle size of EPDM was higher than GTR's, which would be a mechanical property deteriorating factor in itself. The main reason can be the limited energy absorption of rubbery fillers by localized deformation in intraspherulitic structure of PP during the impact test. Brittle failure of the blend is initiated by the rubber

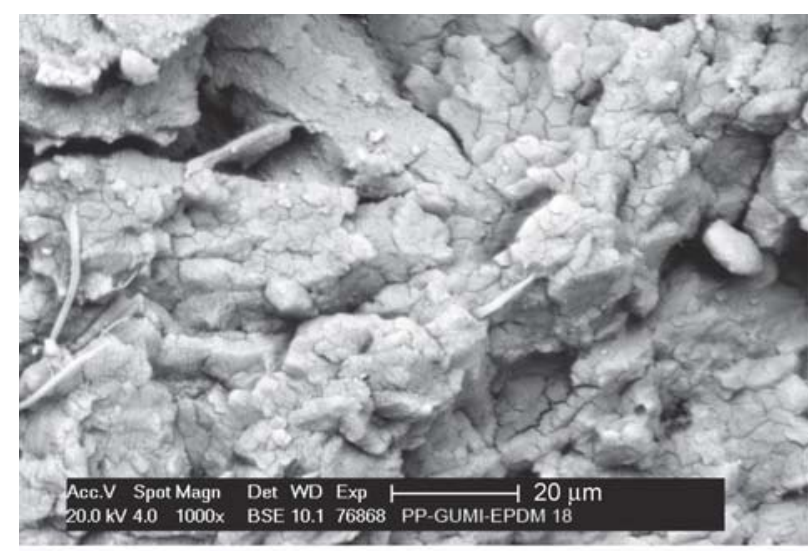

a)

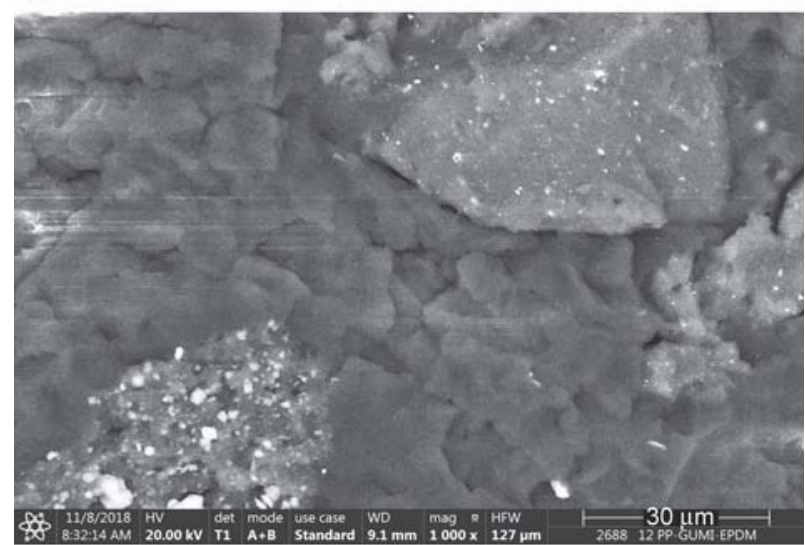

b)

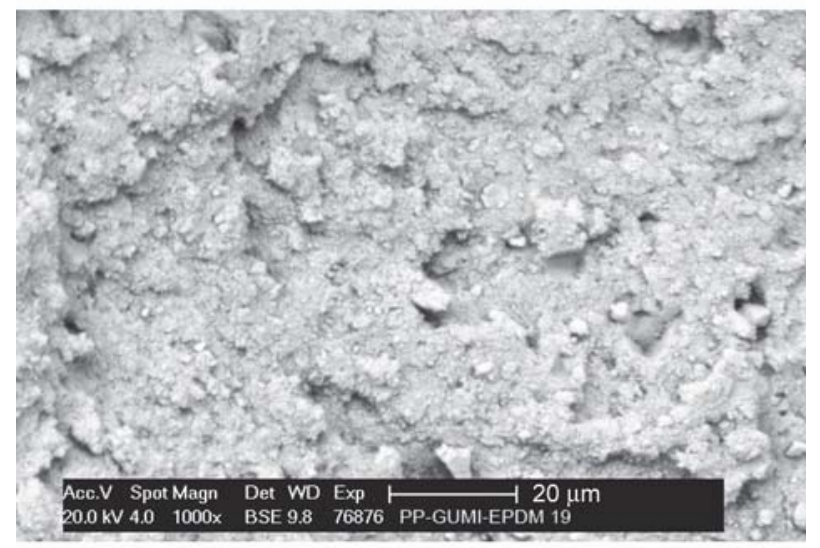

c)

Figure 9. SEM micrographs of 90/10 PP/GTR:EPDM blends with elastomer ratios (a) 1:3, (b) 1:1 and (c) $3: 1$. particles acting as frozen bodies and the difference in impact behavior of the two fillers caused the trends in PP blends observed [36].

Since PP content of the specimens was $90 \mathrm{wt} \%$, crystallinity of PP had a momentous impact on the tensile modulus (Figure $5 b$ ) of the blends.

SEM micrographs of the blends were recorded after tensile measurements. Morphology of the blends based on different elastomer ratios were shown in Figure 9. All of the samples had smooth surface indicating rigid behavior because of the crystalline structure of PP. Low values of elongation at break were confirmed by those micrographs. Significant differences cannot be realized among the micrographs of samples with GTR:EPDM elastomer ratio 1:3 (Figure 9a), 1:1 (Figure $9 b$ ) and 3:1 (Figure 9c). Voids cannot be identified at the interfaces of rubbery and PP phases.

Elastomer ratio of 1:1 GTR:EPDM was chosen for impact assessment of compatibilizing additives at $90 \mathrm{wt} \%$ PP content of the blends because extreme differences could not be noticed between the distinct elastomer ratios applied. It can be stated that results were independent of elastomer ratios which can be advantageous in the future concerning actual access to raw material waste.

\subsection{Impact assessment of compatibilizing additives}

Additives were incorporated into the blend in $0.1 \mathrm{wt} \%$ based on previous own experiences in blends based on PP matrices. That additive concentration can be considered as a really low level, which might be attractive in the point of view of economic factors.

Studying the characters of AD-1 and AD-2 was essential and interesting in terms of additive properties. Spectacular differences could not be recognized among them considering classical analytical properties (acid number and saponification number) which give information about the ratios of anhydride and half-ester functional groups in the structure. All four functional groups can be found in the two additives in almost the same ratios based on the results of FTIR integration (Table 2) [37]. The weight average molecular weight of AD-2 was higher by $790 \mathrm{~g} / \mathrm{mol}$ compared to $\mathrm{AD}-1$ and the polydispersity indices referred to similar distribution curves. As additives may function in different ways at higher temperatures, investigation of the rheological behavior, firstly the temperature dependency was found to be important. Therefore, rheological properties (complex viscosity, 

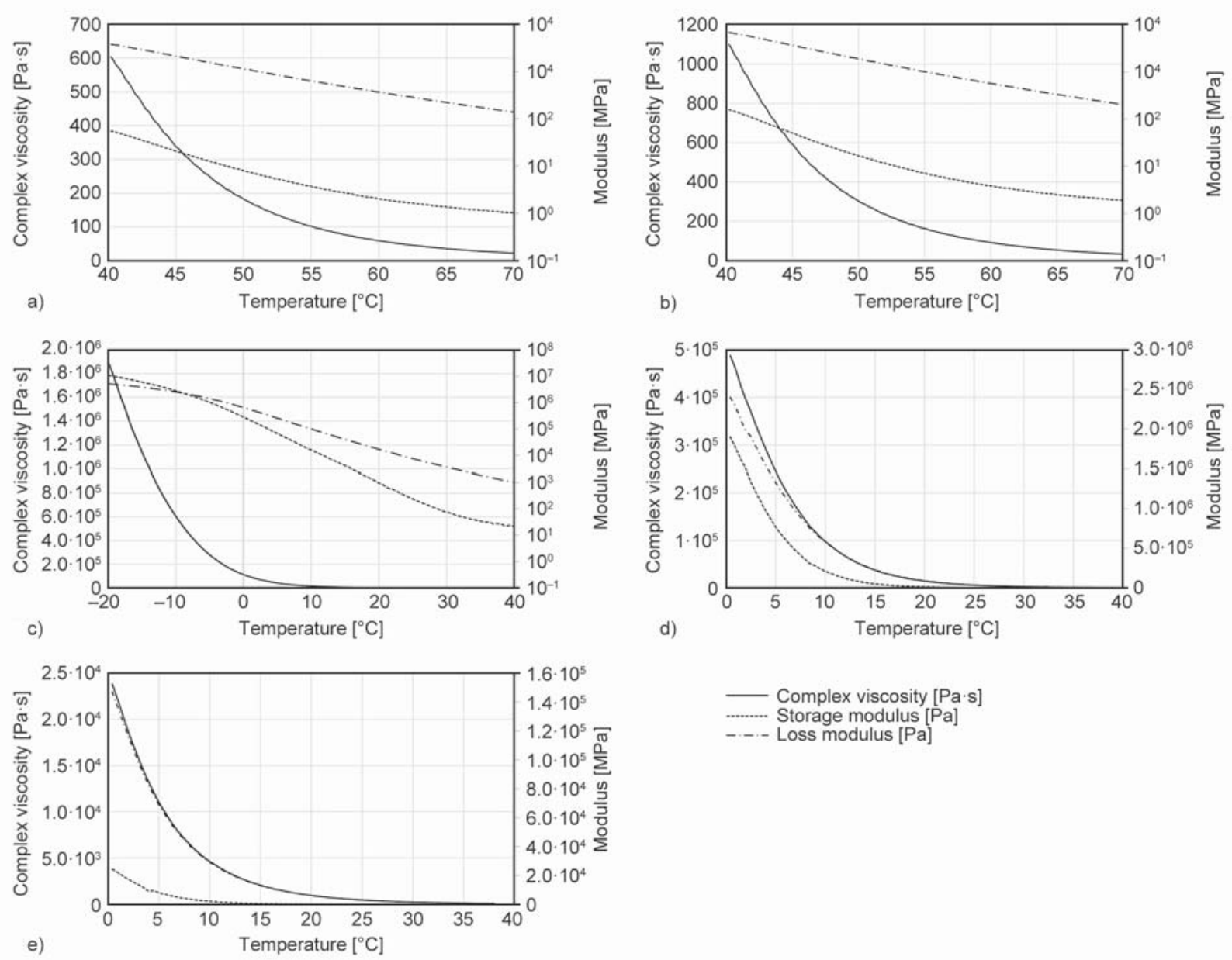

Figure 10. Rheological properties (complex viscosity, storage modulus, loss modulus) of experimental additives as function of temperature: (a) AD-1, (b) AD-2, (c) AD-3, (d) AD-4 and (e) AD-5.

storage modulus, loss modulus) (Figure 10) were studied in the same temperature range because of their similar analytical features. Complex viscosity of AD-2 doubled compared to the values of AD-1 considering nearly the entire range confirming the relation between the molecular weights of them. Preferable tensile strength (Figure 11) could be achieved by application of AD-2 than by AD-1 in the blend while impact strength (Figure 12) changed inversely at room temperature. That might be explained with

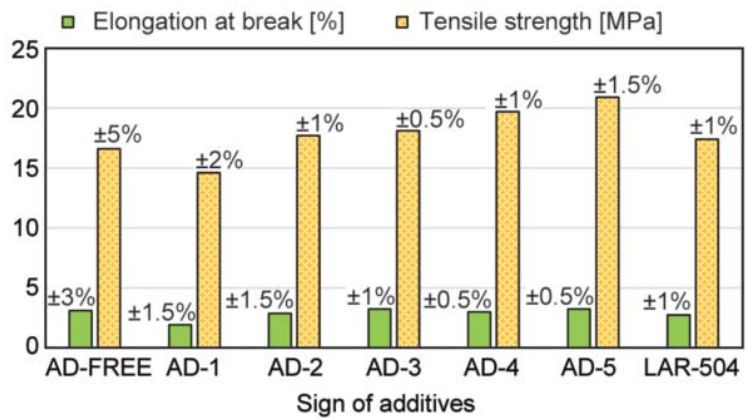

Figure 11. Effect of $0.1 \mathrm{wt} \%$ experimental additives and a commercial one on elongation at break and tensile strength in 90/10(1:1) PP/GTR:EPDM blend. plasticization behavior of additives indicating by the differences in complex viscosities and average molecular weights causing. Plasticization effect of AD-1 can be advantageous in the point of view of impact strength but disadvantageous in terms of tensile strength. Impact strength of the blends with the two additives at lower temperature showed no differences which phenomenon might be due to the disappearance of plasticization effect of AD-1 at that temperature.

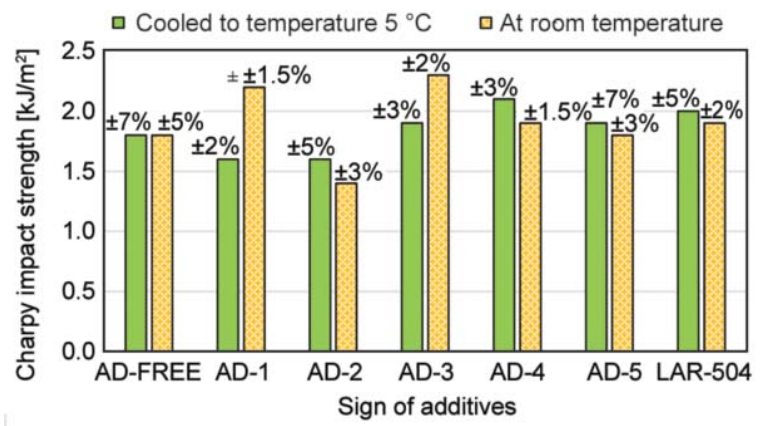

Figure 12. Effect of $0.1 \mathrm{wt} \%$ experimental additives and a commercial one on Charpy impact strength in 90/10(1:1) PP/GTR:EPDM blend. 
AD-3 possessed half-ester groups in the greatest ratio and lowest polydispersity index among all the experimental additives applied (Table 2). Homogeneous distribution of additive functional groups might have been provided by the low polydispersity. AD-3 was able to have the most positive effect on Charpy impact strength (Figure 12) taking in mind the values of cooled and at room temperature measured samples as well. In the latter case $28 \%$ improvement could be experienced. Adding of LAR 504 resulted in balanced values of cooled and at room temperature measured samples. Highest level of complex viscosity was shown by AD- 4 at $5{ }^{\circ} \mathrm{C}$, which was evidenced by favorable impact strength of the cooled blend as well. Nevertheless slope the ramp of the complex viscosity curve was drastic, thus AD-3 performed the best for Charpy impact strength at room temperature because of the successful conservation of relatively higher value of complex viscosity. AD-4 could be characterized by the second lowest weight average molecular weight after AD-1 and the second polydispersity after AD-3. Ratios of functional groups were balanced to each other in AD-4, such as in AD-1

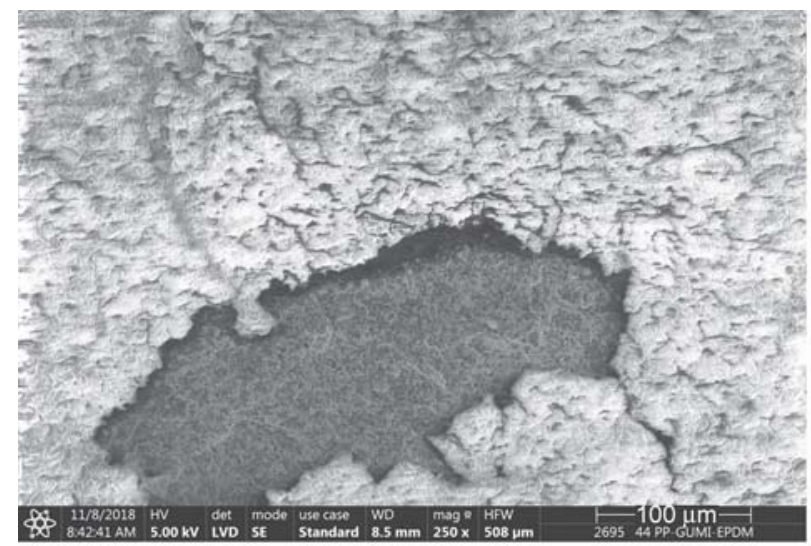

a)

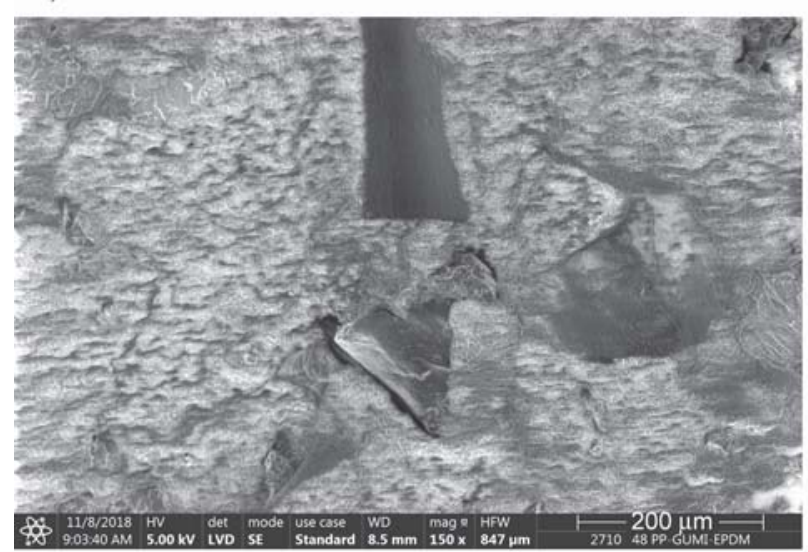

c) and AD-2. Complex viscosity of AD-4 was higher compared to the value of AD-5. No plasticization effect of AD-4 could be determined since both of tensile strength and impact strength was increased set side by side to the additive free blend, so the positive interaction was noticeable.

AD-5 could be characterized by longer copolymer chain, predominant presence of nitrogen containing groups (ester-amide and imide) and only a few percent of anhydride group. AD-5 needed to be highlighted because of its outstanding efficiency in tensile strength (Figure 11) and modulus (Figure 5c), being improved by 26 and 44\%, respectively, in comparison to the additive free specimen. Impact strength remained the same, not being influenced by the temperature increment. Stable and favourable interaction was supposed to be behind the auspicious mechanical properties of the blend.

Performance of commercial compatibilizer was outstanding for none of the properties, the purpose of its application was only to collect information and to compare the efficiency of experimental additives.

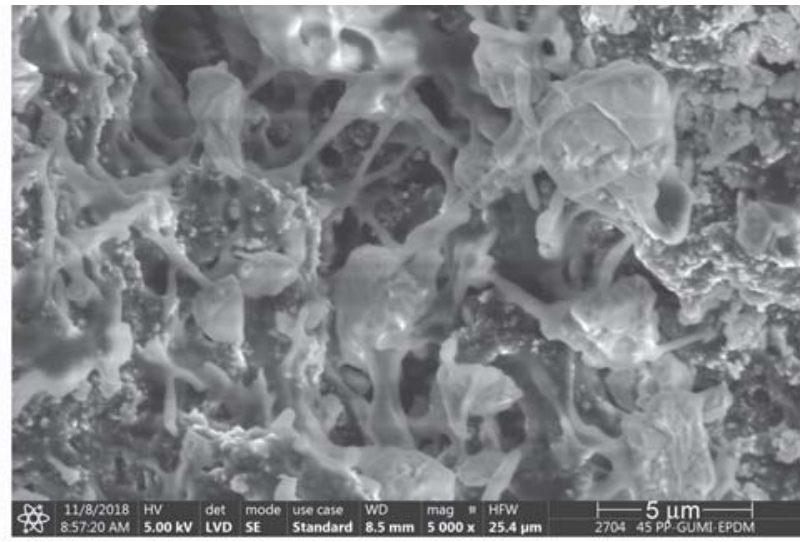

b)

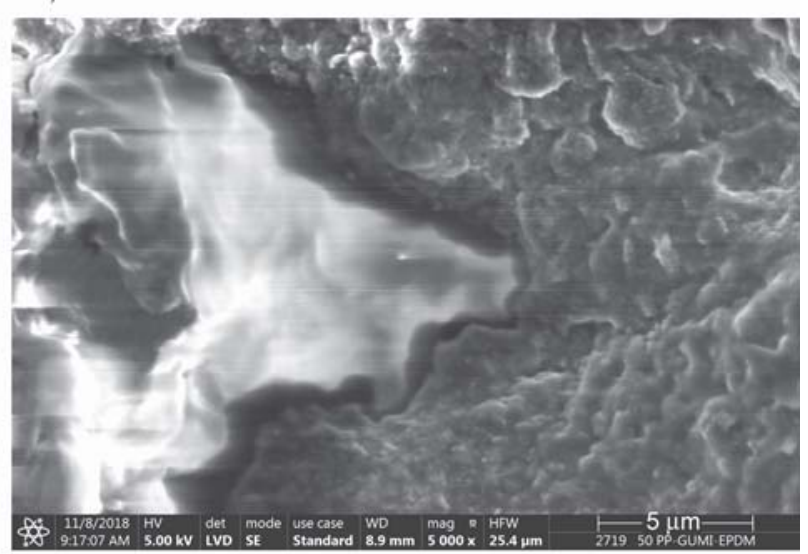

d)

Figure 13. SEM micrographs of 90/10(1:1) PP/GTR:EPDM blends compatibilized by (a) AD-2, (b) AD-3, (c) AD-5 and (d) LAR-504. 
SEM micrographs of some compatibilized blends were represented in the Figure 13. Fine embedding of the particles can be observed in the Figure 13a and in the Figure $13 \mathrm{c}$ of samples compatibilized by AD-2 and AD-5, respectively. Samples compatibilized by AD-3 (Figure 13c) had a really spectacular influence on the microstructure of the blend. It has connected the interfaces of the waste elastomers and polymer by a cobweb-like structure. Addition of compatibilizers might have supported the preferable distribution of the elastomer particles as well. Both of the results of mechanical tests and SEM micrographs have indicated the improvement of compatibility between waste elastomers and PP by incorporation of experimental compatibilizing additives.

\section{Conclusions}

In our study, we have demonstrated a novel type of compatibilizing additives for improving mechanical properties of waste filler containing PP. Effect of waste elastomer concentration was investigated on the mechanical properties of PP based blends. After impact assessment of different elastomer ratios, experimental additives and a commercial one were studied in regard to their structures and improving effect on the blend properties.

Based upon the experimental results we came up to the following conclusion:

- Higher elastomer loading showed better energy absorbance against impact stress.

- Besides boosting of impact strength, conservation and enhancing of prosperous tensile properties were feasible by incorporation of $10 \mathrm{wt} \%$ elastomer.

- Simple physical interaction was suspected between the filler and matrix confirmed by opposite change in impact and tensile strengths and FT-IR spectra of samples without any compatibilizers.

- Investigation and quest for accessible waste raw materials possesses outstanding importance in order to achieve interoperability.

- EPDM and PP were found to be more compatible with each other than GTR and PP.

- Application of different elastomer ratios (GTR to EPDM) can be stated not to have considerable effect on the mechanical properties of the blends.

- Preferable tensile properties and impact strength could be achieved by incorporation of the proper experimental additives (having anhydride, halfester, ester-amide and imide functional groups) while effect of commercial additive was not considerable on any of the properties.

- Rheological properties of additives were confirmed to be essential for the additives to fulfill their role at different temperature levels.

Selection of the suitable additive structure was proved to be really important but the proper molecular weight and complex viscosity should be also achieved at the same time in order to avoid plasticization side effect of the additive in the blend. Temperature dependence of complex viscosity besides the stability of the additive were also substantial factors in regard to the processing opportunities and solutions for selecting the best processing method and range of usage field.

Waste rubber containing polymer blends might be applied in almost every part of the life, where the purity is not an outstanding expectation. Different storage boxes might be mentioned as one way of usage among the numerous opportunities. Furthermore sport devices can be prepared based on waste elastomer containing PP blends as well, where products suffer from dynamic stresses not only at room temperature but also at lower temperature.

\section{Acknowledgements}

The described paper was carried out as a part of the EFOP3.6.1-16-0015 project 'Comprehensive Institutional Development Program' implemented in the framework of the Széchenyi 2020. The realization of this project is supported by the European Union, co-financed by the European Social Fund.

\section{References}

[1] He X., Shi J., Wu L., Jiang P., Liu B.: Study on synergistic toughening of polypropylene with high-density polyethylene and elastomer-olefin block copolymers under ultrasonic application. Composites Science and Technology, 161, 115-123 (2018).

https://doi.org/10.1016/j.compscitech.2018.03.044

[2] Prut E. V., Zhorina L. A., Novikov D. D., Gorenberg A. Y., Vladimirov L. V., Berlin A. A.: Structure and properties of blends based on ground rubber tires and thermoplastics. Mendeleev Communications, 27, 405-406 (2017).

https://doi.org/10.1016/j.mencom.2017.07.030

[3] Ma L-F., Bao R-Y., Dou R., Zheng S-D., Liu Z-Y., Zhang R-Y., Yang M-B., Yang W.: Conductive thermoplastic vulcanizates (TPVs) based on polypropylene (PP)/ethylene-propylene-diene rubber (EPDM) blend: From strain sensor to highly stretchable conductor. Composites Science and Technology, 128, 176-184 (2016). https://doi.org/10.1016/j.compscitech.2016.04.001 
[4] Chen F., Qiu B., Shangguan Y., Song Y., Zheng Q.: Correlation between impact properties and phase structure in impact polypropylene copolymer. Materials and Design, 69, 56-63 (2015).

https://doi.org/10.1016/j.matdes.2014.12.052

[5] Lima P., da Silva S. P. M., Olivieira J., Cocta V.: Rheological properties of ground tyre rubber based thermoplastic elastomeric blends. Polymer Testing, 45, 58-67 (2015).

https://doi.org/10.1016/j.polymertesting.2015.05.006

[6] Benmesli S., Riahi F.: Dynamic mechanical and thermal properties of a chemically modified polypropylene/natural rubber thermoplastic elastomer blend. Polymer Testing, 36, 54-61 (2014).

https://doi.org/10.1016/j.polymertesting.2014.03.016

[7] Karger-Kocsis J., Mészáros J., Bárány T.: Ground tyre rubber (GTR) in thermoplastics, thermosets, and rubbers. Journal of Materials Science, 48, 1-38 (2013). https://doi.org/10.1007/s10853-012-6564-2

[8] Mészáros L., Bárány T., Czvikovszky T.: EB-promoted recycling of waste tire rubber with polyolefins. Radiation Physics and Chemistry, 81, 1357-1360 (2012). https://doi.org/10.1016/j.radphyschem.2011.11.058

[9] Zhang X., Lu C., Liang M.: Preparation of thermoplastic vulcanizates based on waste crosslinked polyethylene and ground tire rubber through dynamic vulcanization. Journal of Applied Polymer Science, 122, 2110 2120 (2011). https://doi.org/10.1002/app.34293

[10] Sonnier R., Leroy E., Clerc L., Bergeret A., LopezCuesta J-M., Bretelle A-S., Ienny P.: Compatibilizing thermoplastic/ground tyre rubber powder blends: Efficiency and limits. Polymer Testing, 27, 901-907 (2008). https://doi.org/10.1016/j.polymertesting.2008.07.003

[11] da Costa H. M., Ramos V. D.: Analysis of thermal properties and rheological behavior of LLDPE/EPDM and LLDPE/EPDM/SRT mixtures. Polymer Testing, 27, 27-34 (2008). https://doi.org/10.1016/j.polymertesting.2007.08.001

[12] Grigoryeva O., Fainleib A., Grenet J., Saiter J. M.: Reactive compatibilization of recycled polyethylenes and scrap rubber in thermoplastic elastomers: Chemical and radiation-chemical approach. Rubber Chemistry and Technology, 81, 737-752 (2008).

https://doi.org/10.5254/1.3548229

[13] Asaro L., Gratton M., Seghar S., Hocine N. A.: Recycling of rubber wastes by devulcanization. Resources, Conservation and Recycling, 133, 250-262 (2018). https://doi.org/10.1016/j.resconrec.2018.02.016

[14] Ramarad S., Khalid M., Ratnam C. T., Luqman Chuah A., Rashmi W.: Waste tire rubber in polymer blends: A review on the evolution, properties and future. Progress in Material Science, 72, 100-140 (2015). https://doi.org/10.1016/j.pmatsci.2015.02.004

[15] Forrest M. J.: Overview of the world rubber recycling market. in 'Recycling and re-use of waste rubber' (ed.: Forest M. J.) Rapra, Shawbury, 17-30 (2014).
[16] Carné P. C.: Study of compatibilization methods for high density polyethylene and ground tyre rubber: Exploring new routes to recycle scrap tyres. PhD thesis, Polytechnical University of Catalonia, (2009).

[17] Hrdlička Z., Cebriá P. M. M., Štefan V., Kuta A.: Thermoplastic elastomeric blends based on waste tires and polyethylene: The role of rubber particle size. Progress in Rubber, Plastics and Recycling Technology, 32, 129142 (2016). https://doi.org/10.1177/147776061603200302

[18] Prut E. V., Solomatin D. V., Kuznetsova O. P.: Rheological behaviors of blends based on polypropylene and EPDM rubber powder. Mendeleev Communications, 27, 318-320 (2017). https://doi.org/10.1016/j.mencom.2017.05.035

[19] Huntink N. M., Datta R. N.: Durability of rubber compounds. in 'Rubber technologist's handbook' (eds.: White J., De S. K., Naskar K.) Rapra, Shawbury, Vol 2, 309-342 (2009).

[20] Sonnier R., Leroy E., Clerc L., Bergeret A., LopezCuesta J. M.: Polyethylene/ground tyre rubber blends: Influence of particle morphology and oxidation on mechanical properties. Polymer Testing, 26, 274-281 (2007).

https://doi.org/10.1016/j.polymertesting.2006.10.011

[21] Sienkiewicz M., Kucinska-Lipka J., Janik H., Balas A.: Progress in used tyres management in the European Union: A review. Waste Management, 32, 1742-1751 (2012).

https://doi.org/10.1016/j.wasman.2012.05.010

[22] Song P., Li S., Wang S.: Interfacial interaction between degraded ground tire rubber and polyethylene. Polymer Degradation and Stability, 143, 85-94 (2017). https://doi.org/10.1016/j.polymdegradstab.2017.06.020

[23] Stelescu D. M., Airinei A., Homocianu M., Fifere N., Timpu D., Aflori M.: Structural characteristics of some high density polyethylene/EPDM blends. Polymer Testing, 32, 187-196 (2013). https://doi.org/10.1016/j.polymertesting.2012.10.010

[24] Hassan M. M., Badway N. A., Elnaggar M. Y., Hegazy E-S. A.: Effects of peroxide and gamma radiation on properties of devulcanized rubber/polypropylene/ethylene propylene diene monomer formulation. Journal of Applied Polymer Science, 131, 406011/1-406011/10 (2014). https://doi.org/10.1002/app.40611

[25] Formela K., Korol J., Saeb M. R.: Interfacially modified LDPE/GTR composites with non-polar elastomers: From microstructure to macro-behavior. Polymer Testing, 42, 89-98 (2015). https://doi.org/10.1016/j.polymertesting.2015.01.003

[26] Mali M. N., Arakh A. A., Dubey K. A., Mhaske S. T.: Influence of triallyl cyanurate as co-agent on gamma irradiation cured high density polyethylene/reclaimed tire rubber blend. Radiation Physics and Chemistry, 131, 66-72 (2017). https://doi.org/10.1016/j.radphyschem.2016.10.020 
[27] Lima P., Oliveira J., Costa V.: Partial replacement of EPDM by GTR in thermoplastic elastomers based on PP/EPDM: Effects on morphology and mechanical properties. Journal of Applied Polymer Science, 131, 40160/1-40160/10 (2014).

https://doi.org/10.1002/app.40160

[28] Tóth B., Varga Cs., Bartha L.: Olefin-maleic-anhydride copolymer based additives: A novel approach for compatibilizing blends of waste polyethylene and crumb rubber. Waste Management, 38, 65-71 (2015).

https://doi.org/10.1016/j.wasman.2015.01.004

[29] Punnarak P., Tantayanon S., Tangpasuthadol V.: Dynamic vulcanization of reclaimed tire rubber and high density polyethylene blends. Polymer Degradation and Stability, 91, 3456-3462 (2006).

https://doi.org/10.1016/j.polymdegradstab.2006.01.012

[30] Bucknall C. B.: Deformation mechanism in rubbertoughened polymers. in 'Polymer blends' (eds.: Paul R. D., Bucknall C. B.) Wiley, New York, Vol 2, 84-116 (2000).

[31] van der Wal A., Gaymans R. J.: Polypropylene-rubber blends: 5. Deformation mechanism during fracture. Polymer, 40, 6067-6075 (1999).

https://doi.org/10.1016/S0032-3861(99)00216-5

[32] Giessen E. V. D., Estevez R., Pijnenburg K. G. W., Tijssens M. G. A.: Computational modeling of failure processes in polymers. in 'European Conference on Computational Mechanics. Munich, Germany’ p.20 (1999).
[33] Lourenço E., Felisberti M. I.: Thermal and mechanical properties of in situ polymerized PS/EPDM blends. European Polymer Journal, 42, 2632-2645 (2006). https://doi.org/10.1016/j.eurpolymj.2006.06.022

[34] Dányádi L., Janecska T., Szabó Z., Nagy G., Moczó J., Pukánszky B.: Wood flour filled PP composites: Compatibilization and adhesion. Composites Science and Technology, 67, 2838-2846 (2007).

https://doi.org/10.1016/j.compscitech.2007.01.024

[35] Kumar C. R., Fuhrman I., Karger-Kocsis J.: LDPE-based thermoplastic elastomers containing ground tire rubber with and without dynamic curing. Polymer Degradation and Stability, 76, 137-144 (2002).

https://doi.org/10.1016/S0141-3910(02)00007-1

[36] Mohamad N., Zainol N. S., Rahim F. F., Maulod H. E. A., Rahim T. A., Shamsuri S. R., Azam M. A., Yaakub M. Y., Abdollah M. F. B., Manaf M. E. A.: Mechanical and morphological properties of polypropylene/epoxidized natural rubber blends at various mixing ratio. Procedia Engineering, 68, 439-445 (2013). https://doi.org/10.1016/j.proeng.2013.12.204

[37] Varga Cs.: Production and investigation of compatibilizing additives for polymer composites (in Hungarian). $\mathrm{PhD}$ thesis, University of Pannonia (2011). 